Editorial

\section{Inaugural Issue of JRMO}

\author{
Bernard T. Lee, MD, MBA, MPH, FACS ${ }^{1}$ \\ ${ }^{1}$ Department of Surgery, Beth Israel Deaconess Medical Center, \\ Harvard Medical School, Boston, Massachusetts
}

J Reconstr Microsurg Open 2016;1:1.

Drs. Berish Strauch and Lee Landres founded the Journal of Reconstructive Microsurgery (JRM) in 1984 to share ideas, innovations, and research from a growing community of microsurgeons. In 2007, its second Editor-in-Chief, Dr. Peter Neligan, launched the online platform in response to a steady increase in manuscript submissions. Today, JRM receives nearly 300 case studies, original articles, and review papers for consideration each year. JRM is committed to publishing groundbreaking techniques and relevant scientific findings for the practicing microsurgeon. Its accomplished and diverse cadre of reviewers ensures that JRM publishes content that is essential to the field of microsurgery, but also is novel, exciting, and clinically practical. Due to limited space, we find ourselves rejecting a significant number of truly excellent papers.

Now, in its 32nd year, JRM offers a companion publication, the Journal of Reconstructive Microsurgery Open (JRMO). JRMO is an Open Access platform that provides an alternative opportunity for authors to share research and techniques with the growing, global community of microsurgeons. JRMO welcomes case studies and original articles focusing on reconstructive surgery of the breast, head and neck reconstruction, complex hand surgery, nerve regeneration and repair, surgical robotics, and new ideas and innovations in the field. Manuscripts are subject to the same rigorous peer review process as its parent journal, JRM.

We are excited to present the inaugural issue of the JRMO, featuring 18 papers that describe management of lower extremity defects and head and neck cancers, intensive care unit nurse training for free-flap monitoring, and impressive and helpful innovations for solving complex reconstructive problems in the operating room. Our premier issue will be available in print, but all articles published in JRMO are easily accessible in full online. We are grateful for the excellent quality of JRM and JRMO submissions and encourage all members of the microsurgery community to continue to share your research, instructive cases, and innovations with us.
Address for correspondence

Bernard T. Lee, MD, MBA, MPH,

FACS, Department of Surgery,

Beth Israel Deaconess Medical

Center, Harvard Medical School,

110 Francis Street, Suite 5A,

Boston, MA 02215, USA

(e-mail: btlee@bidmc.harvard.edu).
DOI http://dx.doi.org/ 10.1055/s-0036-1584516. ISSN 2377-0813.
Copyright $\odot 2016$ by Thieme Medical Publishers, Inc., 333 Seventh Avenue, New York, NY 10001, USA.

Tel: +1(212) 584-4662.
License terms

(c) (i) $\ominus$ (\$) 